Intecoms: Journal of Information Technology and Computer Science

Volume 1 Nomor 1, Juni 2018

e-ISSN : 2614-1574

p-ISSN : 2621-3249

DOI : https://doi.org/10.31539/intecoms.v1i1.160

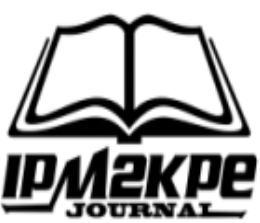

\title{
PERANCANGAN SIMULASI PEMBELAJARAN KRIPTOGRAFI KLASIK MENGGUNAKAN METODE WEB BASED LEARNING
}

\section{DESIGN OF SIMULATION LEARNING CLASSIC CRIPTOGRAPHY USING WEB BASED LEARNING METHOD}

\author{
Jefril Rahmadoni \\ UIN Sulthan Thaha Saifuddin, Jambi \\ jefril.doni@gmail.com
}

\begin{abstract}
One of the main problems in the education system in Indonesia is a quality problem and the results of the learning process. This problem relates to the provision of learning materials and materials that have not been widely accessible without being limited by the constraints of distance and time. In realizing this requires a change in the paradigm of the learning process has been applied so far as implementing $e$ learning. To achieve these objectives developed model of e-learning by using web-based learning. Web based learning (WBL) is the learning associated with the teaching materials are presented via a web browser. Web-based learning applications created using programming languages PHP and MySQL. The results of a web-based learning can facilitate students in the learning process and provide information services in understanding a material that has been displayed on web-based learning site
\end{abstract}

Keywords : E-learning, Web Based Learning, Classic Cryptography

\begin{abstract}
ABSTRAK
Salah satu masalah utama pada sistem pendidikan di Indonesia adalah masalah kualitas dan hasil dari proses pembelajaran. Masalah ini berhubungan dengan penyediaan materi dan bahan belajar yang belum dapat diakses secara luas tanpa dibatasi oleh kendala jarak dan waktu. Dalam mewujudkan hal ini dibutuhkan perubahan pada paradigma proses belajar mengajar yang telah diterapkan selama ini seperti mengimplementasikan e-learning. Untuk mencapai tujuan tersebut dikembangkan model pembelajaran elearning dengan menggunakan metode web based learning. Web based learning (WBL) adalah pembelajaran yang berhubungan dengan materi ajar yang disajikan melalui web browser. Aplikasi web based learning dibuat dengan menggunakan bahasa pemrograman PHP dan MySQL. Hasil dari pembelajaran jarak jauh berbasis web dapat mempermudah mahasiswa dalam proses belajar mengajar dan memberikan layanan informasi dalam memahami suatu materi yang telah ditampilkan pada situs pembelajaran web based learning.
\end{abstract}

Kata Kunci : E-learning, Web Based Learning, Kriptografi Klasik

\section{PENDAHULUAN}

Salah satu masalah utama pada sistem pendidikan di Indonesia adalah masalah kualitas dan hasil dari proses pembelajaran. Masalah ini berhubungan dengan penyediaan materi dan bahan belajar yang belum dapat diakses secara luas tanpa dibatasi oleh kendala jarak dan waktu. Mempersiapkan sumber daya manusia dengan memberdayakan teknologi informasi terutama dalam menghasilkan tenaga pendidik dan alumni komperatif menjadi sesuatu yang mendesak. Reinassance academic melalui inovasi teknologi untuk meningkatkan keunggulan kualitas akademik menjadi sangat penting sebagai center of exdellence melalui tekonologi informasi yang menjadi tulang punggung keberhasilan cyber education. Pemanfaatan ICT (Information and Communication Technologies) biasanya digunakan untuk searching perpustakaanm 
ensiklopedia, jurnal ilmuah, beasiswa dan research grant atau untuk keperluan-keperluan lainnya.

Salah satu perbedaan pembelajaran tradisonal dengan $e$ learning yang menggunakan web adalah terletak pada siapa yang menjadi pusat dalam pembelajaran (Prasetio, 2012). Pada kelas tradisional, guru atau dosen dianggap sebagai orang yang serba tahu di bidangnya dan ditugaskan untuk mentransfer ilmu pengetahuan kepada anak didiknya, sedangkan di dalam pembelajaran e-learning berbasis web fokus utamanya adalah pelajar atau mahasiswa. Menurut Kalaivani (2015) e-learning adalah semua bentuk dari elektronik yang mendukung dalam pembelajaran dan pengajaran. Dan Shahid dan Abbas (2014) menerangkan bahwa e-learning adalah cara yang paling mudah dan cepat dalam perkuliahan jarak jauh dengan menyediakan bahan-bahan pembelajaran menggunakan internet yang menjadi tren di negera berkembang.

Dari beberapa pendapat ahli di atas, peneliti menyimpulkan bahwa $e$ learning adalah pembelajaran jarak jauh (distance learning) yang memanfaatkan teknologi komputer, jaringan komputer atau internet. E-learning memungkinkan pembelajaran untuk belajar melalui komputer ditempat mereka masing-masing tanpa harus secara fisik pergi mengikuti pelajaran/perkuliahan di kelas.

E-learning sendiri memiliki beberapa kelebihan yang mana petunjuk tentang manfaat penggunaan internet, khususnya dalam pendidikan terbuka dan jarak jauh (soekartawi, 2003).

Tersedianya fasilitas $e$ moderating di mana dosen dan mahasiswa dapat berkomunikasi secara mudah melalui fasilitas internet secara regular atau kapan saja kegiatan berkomunikasi itu dilakukan dengan tanpa dibatasi oleh jarak, tempat dan waktu.

Dosen dan mahasiswa dapat menggunakan bahan ajar atau petunjuk belajar yang terstruktur dan terjadwal melalui internet, sehingga keduanya bisa saling menilai sampai berapa jauh bahan ajar dipelajari. Mahasiswa dapat belajar atau mengulang kembali bahan ajar setiap saat dan di mana saja kalau diperlukan mengingat bahan ajar tersimpan di komputer.

Baik dosen maupun mahasiswa dapat melakukan diskusi melalui internet yang dapat diikuti dengan jumlah peserta yang banyak, sehingga menambah ilmu pengetahuan dan wawasan yang lebih luas.

Berubahnya peran mahasiswa dari yang biasanya pasif menjadi aktif. Relatif lebih efisien. Misalnya bagi mereka yang tinggal jauh dari perguruan tinggi atau sekolah konvensional (Soekarwati, 2003).

Meskipun demikian pemanfaatan internet untuk pembelajaran atau $e$ learning juga tidak terlepas dari berbagai kekurangan.

Berbagai kritik, salah satunya antara lain: Kurangnya interaksi antara dosen dan mahasiswa atau bahkan antar mahasiswa itu sendiri. Kurangnya interaksi ini bisa memperlambat terbentuknya values dalam proses belajar dan mengajar.

Kecenderungan mengabaikan aspek akademik atau aspek sosial dan sebaliknya mendorong tumbuhnya aspek bisnis/komersial. Proses belajar dan mengajarnya cenderung ke arah pelatihan daripada pendidikan. Tidak semua tempat tersedia fasilitas internet. Kurangnya tenaga yang mengetahui dan memiliki ketrampilan internet. Kurangnya penguasaan bahasa komputer. 
Standar LTSA merupakan standar internasional sistem pembelajaran yang dikembangkan berdasarkan IEEE 1484 Learning Standards Committee (LTSC) oleh Farance Incorporational, divisi Edutool, yang merupakan arsitektur tingkat tinggi yang berfokus pada masalah teknologi pembelajaran, pelatihan berbasis komputer, sistem pendukung performasi elektronik, instruksi berbantuan komputer, dan lain-lain (Yusuf, Wahyuni dan Saim, 2010).

Mata kuliah keamanan komputer adalah salah satu mata kuliah yang diajarkan pada jurusan Sistem Informasi yang mana pada mata kuliah kemanan komputer ini ada diajarkan tentang kriptografi yang lebih spesifik adalah kriptografi klasik. Pelajaran kriptografi klasik ini salah satu pelajaran yang tidak disukai oleh rata-rata mahasiswa dikarenakan kriptografi klasik ini menggunakan dua algoritma yaitu substitution ciphers dan transposition ciphers.

Pada penelitian kali ini, penulis meneliti bahwa dalam perkuliahan yang biasa dilakukan di dalam kelas bahwa dosen cendrung menggunakan metode tatap muka berupa ceramah, tanya jawab dan diskusi. Metode ini secara prkatis membuat penyampaian ilmu pengetahuan seperti penyampaian materi, diskusi dan pemberian soal latihan menjadi sangat terbatas. Minimalnya media yang dipakai dalam penyampaian materi pembelajaran juga menjadi suatu masalah yang dialami oleh dosen dan mahasiswa. Dalam penyajian materi, dosen menyampaikan pelajaran di depan kelas dan mahasiswa mencatat ke dalam buku catatan, atau menggunakan metode konvensional lainnya. Penyampaian materi kadang tidak tercapai karena keterbatasan waktu dalam satu materi pelajaran.
Hal ini tentu akan menimbulkan beberapa permasalahan dalam pembelajaran seperti kurang pahamnya mahasiswa pemahaman materi-materi yang bersifat teori maupun praktek sehingga nilai akademik yang diperoleh rendah.

\section{METODE PENELITIAN Arsitektur Sistem LTSA}

LTSA menspesifikasikan lima lapisan (layer), tetapi hanya layer 3 yang bersifat normative. Setiap layer menggambarkan sebuah sistem pada level yang berbeda. Berikut ini adalah gambar layer-layer yang ada pada standar LTSA :

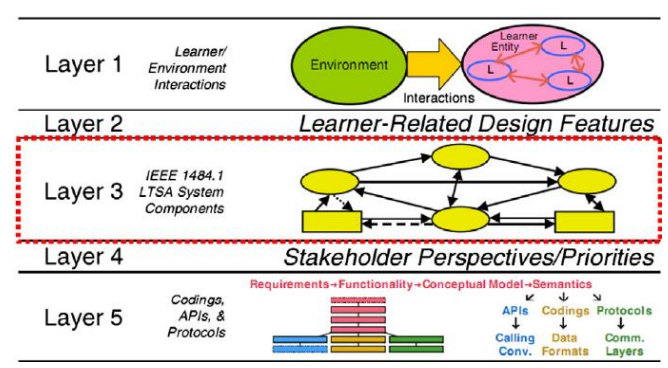

Gambar 1. Arsitektur LTSA

Layer 1 yaitu Learner and Environment Interaction. Layer ini berfokus kepada akuisisi, transfer, pertukaran, formulasi dan penemuan pengetahuan dan atau informasi melalui interaksi dengan lingkungan.

Layer 2 yaitu Learner Related Design Features. Layer ini berfokus kepada pengaruh yang dimiliki learner pada perancangan dari sistem pembelajaran.

Layer 3 yaitu System Components. Layer ini mendeskripsikan komponen dasar arsitektur yang diidentifikasi pada layer 2 .

Layer 4 yaitu Implementation Perspective and Priorities. Layer ini mendeskripsikan sistem pembelajaran dari berbagai perspektif dengan mengacu pada layer 3. Setiap stakeholder memiliki perspektif yang 
berbeda terhadap sistem pembelajaran. Analisis terhadap perspektif dapat menghasilkan verifikasi dan validasi komponen LTSA pada system, penentuan komponen LTSA yang tidak perlu dan perlu ditekankan pada system dan indikasi berbagai prioritas perancangan level tinggi dan level rendah.

Layer 5 yaitu Operational Components and Interoperability (codings, APIs, protocols). Layer ini mendeskripsikan komponen dan antar muka yang bersifat generic dari arsitektur pembelajaran berbasis teknologi informasi seperti yang diidentifikasi pada layer 4 .

\section{Komponen Sistem LTSA}

Pada arsitektur sistem LTSA terdapat 5 layer, namun hanya layer 3 yang merupakan layer normatif, layer lainnya temasuk layer informatif. Normatif adalah istilah yang digunakan dalam LTSA sebagai petunjuk pada spesifikasi sistem secara teknis pada implementasi yang akan dilakukan. Sedangkan Informatif adalah istilah pada LTSA yang cukup membantu dalam perancangan arsitekturnya, namun bukan merupakan hal yang diperlukan untuk mengerti isi dari standar LTSA. Hal ini tidak termasuk spesifikasi teknis dan bukan berasal dari bagian terintegrasi dari standar LTSA.

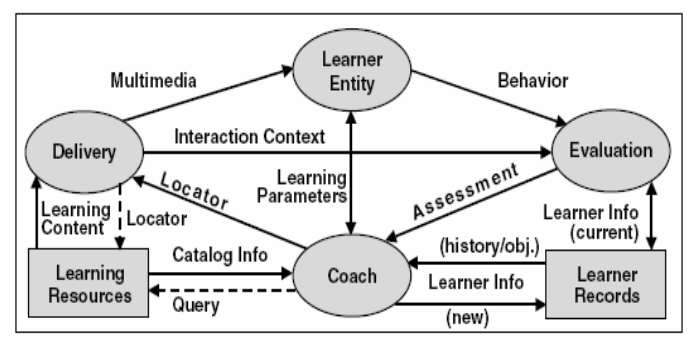

Gambar 2. Komponen Sistem LTSA

Layer ini merupakan sebuah sistem dengan berbagai komponen yang mempresentasikan pengorganisasian sebuah proses pembelajaran dari sudut pandang proses dan data flow. Proses didalam kompenen sistem LTSA dideskripsikan dengan batasan-batasan berupa input, proses (secara fungsionalitas) dan output. Proses pada kompenen sistem LTSA terdiri dari entitas pelajar (learner entity), evaluasi (evaluation), pelatih (coach) dan (delivery). Media penyimpanan data dideskripsikan dengan tipe dari informasi yang disimpan. Penyimpanan data terdiri dari sumber daya pembelajaran (learner resources) dan data hasil pembelajaran (learner record). Aliran data dideskripsikan berdasarkan konektifitas(satu arah, dua arah, konektifitas statis, dinamis dan sebagainya) dan tipe informasi yang dialirkan. Aliran data terdiri dari query, info catalog (catalog info), materi pembelajaran (learning content), locator, multimedia, konteks interaksi (interaction centext), perilaku (behavior), penilaian (assessment), parameter pembelajaran (learning parameters) dan informasi pelajar (learner information).

\section{Web Based Learning (WBL)}

Web based learning (pembelajaran berbasis web) adalah pembelajaran yang berhubungan dengan materi ajar yang disajikan melalui web browser (seperti internet explorer, mozzilla firefox, opera, netscape, dan lain-lain).

\section{Model Pembelajaran Web Based Learning \\ Untuk situs web yang} menyampaikan aspek pembelajaran sangat bervariasi, Maka klasifikasi sangat diperlukan agar mudah untuk ditelaah dan dianalisa. Berdasarkan media dan tingkat interaktifitas web 
based learning, web based learning yang telah diidentifikasikan.

\section{Terminologi E-learning dan Kedudukan Web Learning}

E-learning adalah model pembelajaran yang pelaksanaannya didukung oleh jasa teknologi seperti telepon, audio, videotape, video conference, transmisi satelit atau komputer. Web learning atau terkadang disebut online learning merupakan suatu sistem atau proses untuk melaksanakan kegiatan belajar mengajar jarak jauh melalui aplikasi web dan jaringan internet. Meskipun pada prinsipnya web learning/ web based learning adalah pengembangan $e$ learning dengan berbasis web.

\section{PEMBAHASAN}

\section{Cara Menjalankan Sistem}

E-learning ini diimplementasikan di perkuliahan kemanan komputer, khususnya pada materi kriptografi klasik. Untuk menjelaskan alur kerja yang terkait dengan sistem ini, berikut dijelaskan bagaimana skenario pengujian dari e-learning pembelajaran kriptografi klasik:

1. User membuka halaman utama pada sistem e-learning ini dengan cara mengetik halaman web elearningkriptografi.tk pada web browser. Apabila muncul halaman utama pada sistem e-learning, maka sistem berhasil dijalankan.

2. Pada halaman utama ini, masingmasing user terutama mahasiswa dapat melihat tutorial dari dari pembelajaran kriptografi klasik ini. Apabila tutorial dapat dijalankan, maka sistem berhasil dijalankan.

3. Setelah halaman utama dapat ditampilkan, maka masing-masing user dapat melakukan login berdasarkan username dan password masing-masing user. Apabila user dapat melakukan login, maka login berhasil dilakukan.

4. Setelah user admin melakukan login, admin memilih menu manajemen user untuk mendaftarkan masingmasing user, yaitu dosen dan mahasiswa dengan cara input data user dan kemudian melakukan klik pada tombol register, selanjutnya sistem akan menyimpan data di file user. Apabila admin berhasil mendaftarkan masing-masing user, maka sistem berhasil dijalankan.

5. Masing-masing user dapat memilih menu manajemen forum untuk melakukan komunikasi antar sesama user baik admin, dosen maupun mahasiswa. Apabila user dapat melakukan komunikasi antar sesama user pada menu manajemen forum, maka sistem sukses dijalankan.

6. Pada menu upload dan download, user dapat melakukan aktifitas upload file ke dalam sistem yang kemudian sistem menyimpan file tersebut kedalam file donwload. Selain itu user dapat melakukan aktifitas download file yang ditampilkan sistem berdasarkan data atau file yang disimpan dalam file download. Apabila user dapat melakukan aktifitas upload dan download pada sistem, maka sistem berhasil dijalankan.

7. Pada sistem e-learning ini, user dosen memilih menu soal untuk melakukan aktifitas input soal ujian beserta pilihan jawaban dan kunci jawaban yang kemudian sistem akan menyimpan data kedalam file soal. Apabila soal yang di input oleh dosen berhasil disimpan oleh sistem, maka sistem berhasil dijalankan.

8. Soal yang telah di input oleh dosen dapat dikerjakan oleh mahasiswa pada sistem pada menu soal, kemudian memilih kelas dan mata kuliah serta bab pelajaran yang akan 
diujikan. Dalam mengerjakan soal ujian, mahasiswa menjawab soal ujian satu per satu. Apabila soal pertama telah dijawab, mahasiswa harus melakukan klik tombol next untuk dapat menjawab soal berikutnya. Setelah mahasiswa menjawab semua soal yang diberikan oleh sistem, maka mahasiswa dapat mengetahui langsung nilai ujian dari soal yang telah dijawab. Apabila mahasiswa dapat menjawab semua soal dan langsung mengetahui nilai dari ujian, maka sistem berhasil menjalankan menu soal untuk ujian masing-masing mahasiswa.

9. Pada menu manajemen soal dan memilih sub menu list jawaban mahasiswa, dosen dapat melihat nilai masing-masing mahasiswa. Apabila dosen dapat melihat semua nilai dari masing-masing mahasiswa, maka sistem berhasil dijalankan.

10. Pengujian evaluasi nilai ujian diawali dari pengambilan file jawaban mahasiswa. File jawaban mahasiswa ini akan dibaca oleh sistem untuk dibandingkan dengan file yang berisikan jawaban yang benar. Hasil perbandingan ini akan menentukan nilai dari mahasiswa. Apabila nilai mahasiswa ini $\geq 80$ maka mahasiswa akan dinyatakan lulu, sebaliknya jika $<80$ maka mahasiswa dinyatakan tidak lulus. Hasil ini akan muncul dalam tampilan laporan jawaban mahasiswa dan sekaligus ini merupakan bentuk kriteria sukses dari proses pengujian evaluasi nilai ujian.

11. Pada sistem ini, dosen dapat mengetahui tingkat pemahaman pembelajaran mahasiswa dengan melihat dari nilai ujian dari masingmasing mahasiswa. Apabila lebih dari $50 \%$ mahasiswa mendapat nilai 80 - 100, maka sistem e-learning ini telah mampu meningkatkan pembelajaran dan pemahaman materi ajar pada mahasiswa yang tanpa dibatasi oleh akses jarak dan waktu.

Untuk lebih jelasnya mengenai tampilan e-learning yang di uji-cobakan itu adalah sebagai berikut:

\section{Halaman Utama Admin, Dosen dan Mahasiswa}

Halaman ini adalah halaman muka atau tampilan awal sebelum login oleh masing-masing user. Halaman Utama ini berisi:
a. Header dan Footer
b. Tempat untuk logot atau login bagi semua user
c. Menubar yang terdiri dari Beranda, Profil dan Call Us

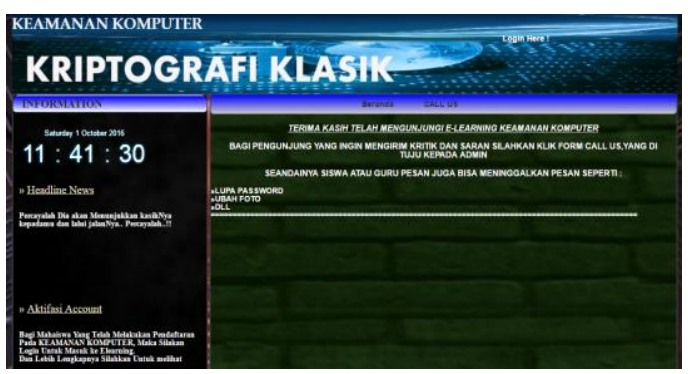

Gambar 3. Halaman Utama

Gambar 3 merupakan halaman utama pada web.

\section{Halaman Login}

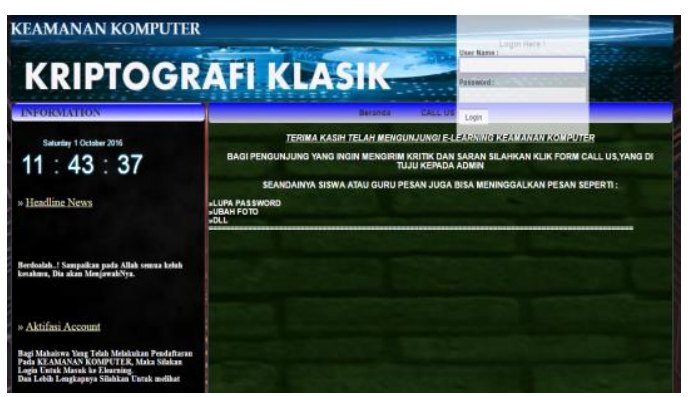

Gambar 4. Halaman Login

Gambar 4 adalah halaman login dimana user memasukkan username dan password agar dapat mengakses menu utama. Untuk pendaftaran tidak dapat dilakukan secara manual. 
Penambahan user hanya bisa dilakukan oleh admin.

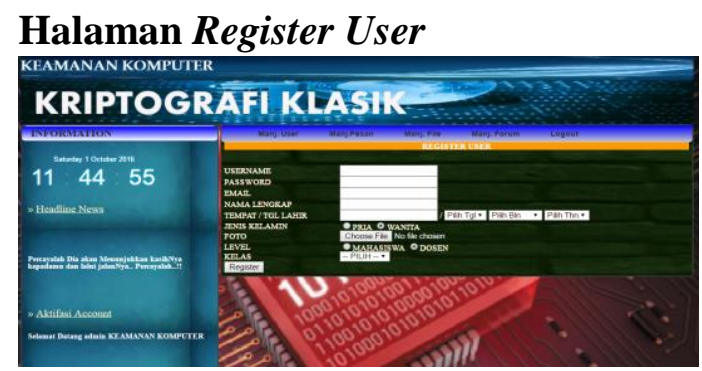

Gambar 5. Halaman Register User

Gambar 5 merupakan halaman register user yang terdiri dari username, password, e-mail, nama lengkap, tempat / tanggal lahir, jenis kelamin, foto, level dan kelas yang mana halaman di isi oleh masing-masing user yang akan mendaftar sebagai user baik mahasiswa maupun dosen.

\section{Halaman Forum}

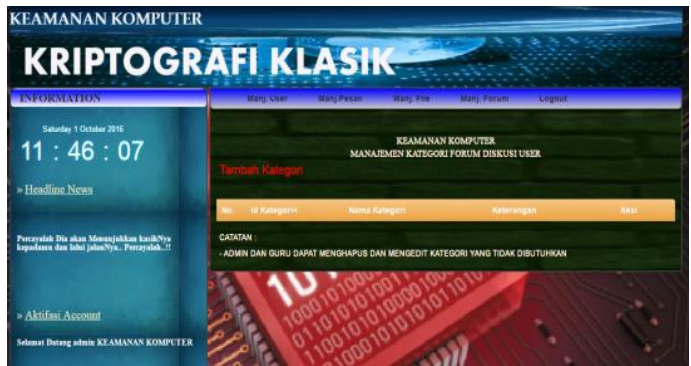

Gambar 6. Halaman Forum

Gambar 6 merupakan halaman forum yang merupakan salah satu tempat belajar atau saling bertanya antar sesama user yang terdiri dari submenu kategori, diskusi, topik dan komentar.

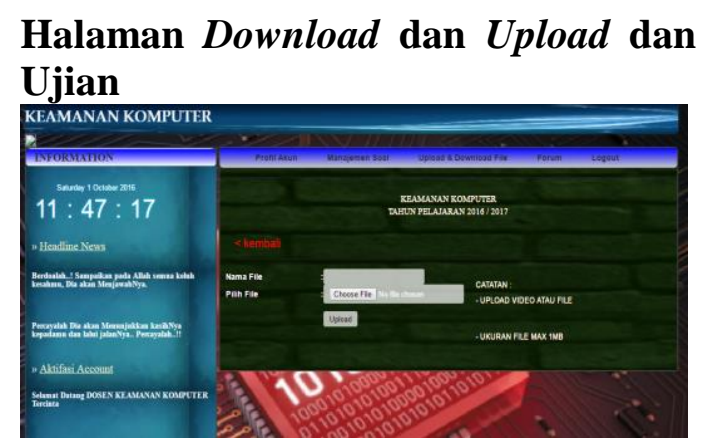

Gambar 7. Halaman Upload

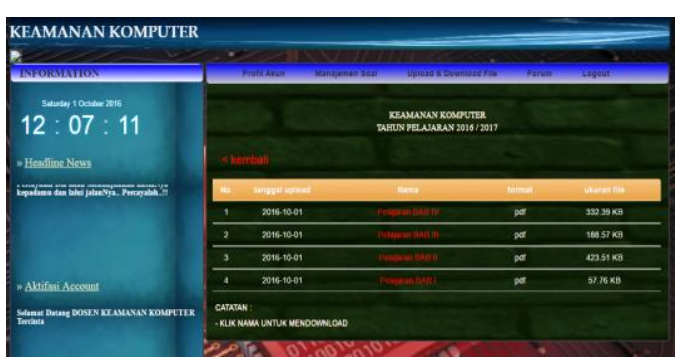

Gambar 8. Halaman Download

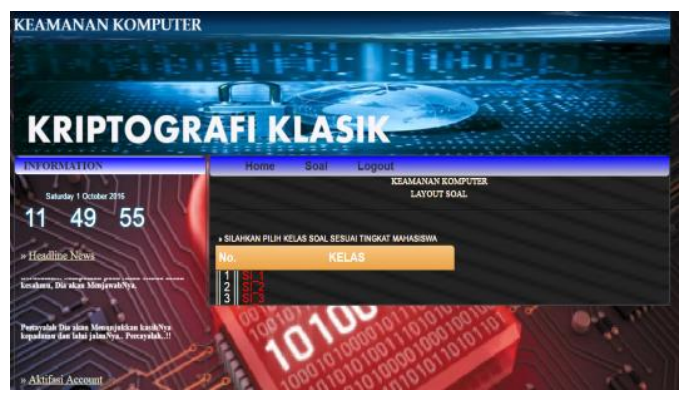

Gambar 9. Halaman Ujian

Pada halaman download dan upload terdapat pada menu masingmasing user yaitu dosen mahasiswa. Dosen dapat melakukan update materi pelajaran dengan cara upload materi pelajaran pada sistem yang kemudian mahasiswa dapat melakukan download materi pelajaran tersebut untuk dipelajari. Mahasiwa dapat melakukan upload tugas yang diberikan oleh dosen yang kemudian dosen dapat melakukan download tugas tersebut untuk kemudian dinilai.

\section{Web Based Learning (WBL)}

$W B L$ (pembelajaran berbasis web) adalah pembelajaran yang berhubungan dengan materi ajar yang disajikan melalui web browser (seperti internet explorer, mozzilla firefox, opera, netscape, dan lain-lain).

Fitur-fitur yang harus ada pada layanan web sehingga bisa disebut web based learning, yaitu:

1. Informasi pelajaran, catatan pengumuman dan jawal.

2. Peta kurikulum.

3. Bahan ajar seperti slide, handout dan artikel. 
4. Komunikasi melalui email dan forum.

5. Penilaian formatif dan sumatif.

6. Alat manajemen siswa (records, statitstics, student tracking).

7. Link ke website terkait baik internal maupun eksternal yang bermanfaat seperti perpustakaan, online database, dan jurnal.

\section{Model Pembelajaran Web Based Learning}

Untuk situs web yang menyampaikan aspek pembelajaran sangat bervariasi, Maka klasifikasi sangat diperlukan agar mudah untuk ditelaah dan dianalisa. Berdasarkan media dan tingkat interaktifitas web based learning, web based learning yang telah diidentifikasikan yang terdiri dari :

1. Teks dan grafik web based learning

Teks dan grafik adalah bentuk yang paling sederhana dalam web based learning program. Hanya menyimpan materi-materi pembelajaran didalam web dan murid/mahasiswa dapat mengaksesnya dengan mudah arena hanya menyampaikan teks dan grafik saja.

2. Interaktif web based learning Model web based learning seperti ini memiliki level interaktifitas yang lebih tinggi dibandingkan model yang pertama (teks dan grafik web based learning). Model ini dilengkapi dengan sarana-sarana latihan atau self test, test entry, colum matching, dan lain- lain.

3. Interktif multimedia web based learning

Kebanyakan program belajar dengan menggunakan model seperti ini biasanya membuat interaksi antara pengajar/dosen dan murid/mahasiswa secara real time melalui audio dan video streaming, interactive web discussion, bahkan audio atau video dekstop conference. Level interaktifitas model ketiga ini paling tinggi diantara yang lainnya dan paling rumit dalam pelaksanaannya, dengan model ini diharapkan dapat mencakup semua kondisi belajar mengajar pada kelas tatap muka.

\section{Terminologi E-learning dan Kedudukan Web Learning}

E-learning adalah model pembelajaran yang pelaksanaannya didukung oleh jasa teknologi seperti telepon, audio, videotape, video conference, transmisi satelit atau komputer. Web learning atau terkadang disebut online learning merupakan suatu sistem atau proses untuk melaksanakan kegiatan belajar mengajar jarak jauh melalui aplikasi web dan jaringan internet. Meskipun pada prinsipnya web learning/ web based learning adalah pengembangan $e$ learning dengan berbasis web.

\section{Defenisi Simulasi}

Simulasi (simulation) adalah pendekatan untuk menyusun suatu model yang logis dari sistem bisnis yang sebenarnya, dan bereksperimen dengan model tersebut untuk mendapatkan pemahaman mengenai perilaku sistem tersebut atau untuk mengevaluasi dampak perubahan dalam asumsi atau potensi perbaikan terhadapnya. Simulasi memberikan kesempatan untuk mengumpulkan sejumlah besar data real time yang mungkin membutuhkan waktu berharihari atau berbulan- bulan untuk dikumpulkan dapat dikumpulkan dalam beberapa menit pada sebuah komputer dan mencegah eksperimen fisik yang berbiaya tinggi. 
Unified Modelling Language (UML)

Menurut Sanjani, Hartati dan Sudarmaningtyas (2014), UML adalah bahasa pemodelan untuk sistem atau perangkat lunak yang berparadigma beriorientasi objek. Pemodelan sesungguhnya digunakan untuk penyederhanaan permasalahanpermasalahan yang kompleks sedemikian rupa sehingga lebih mudah dipelajari dan dipahami.

Pada perkembangan teknik pemrograman berorientasi objek, muncullah sebuah standarisasi bahasa pemrograman untuk pembangunan perangkat lunak yang dibangun dengan menggunakan teknik pemrograman berorientasi objek, yaitu Unified Modelling Languade (UML). UML muncul karena adanya kebutuhan pemodelan visual untuk menspesifikasikan, menggambarkan, membangun, dan dokumentasi dari sistem perangkat lunak (Rosa dan Shalahuddin, 2011), (Sopiah, 2012).

\section{SIMPULAN}

Media pembelajaran e-learning untuk pembelajaran kriptografik klasik pada mahasiswa Universitas Putra Indonesia "YPTK" Padang pada jurusan Sistem Informasi di kelas SI-1 dapat menjadi media belajar yang aktif dan mandiri dengan menggunakan metode web based learning.

Dari hasil pengujian pembelajaran, e-learning dengan menggunakan metode web based learning menjadi suatu media yang dapat disajikan dan diakses secara luas dimana saja dan kapan saja tanpa dibatasi oleh jarak dan waktu. 


\section{DAFTAR PUSTAKA}

Kalaivani, A. (2014). Role of ELearning in the Quality Improvement of Higher Education. Journal Of Humanities And Social Science, 19(11), 15-17

Prasetio, P. (2012). Perancangan dan Implementasi Content Pembelajaran Online Dengan Metode Blended Learning. Jurusan Teknik Elektro-FT, UNSRAT, 1(3), 1-7

Rosa, A., \& Shalahuddin, M. (2013). Rekayasa Proyek Perangkat Lunak. Bandung: Informatika

Sanjani, L. A., Hartati S. J. \& Sudarmaningtyas, P. (2014). Rancang Bangun Sistem Informasi Penggajian Pegawai dan Remunerasi Jasa Medis Pada Rumah Sakit Bedah Surabaya. STMIK STIKOM Surabaya, 3(1)

Shahid, S., \& Abbasi, M. S. (2014). Usability Testing of an ELearning System: A Comparative study of two Evaluation Techniques. Journal of Computer Engineering, 16(6), 39-43

Soekartawi, S. (2003). Prinsip Dasar ELearning: Teori Dan Aplikasinya Di Indonesia. Jurnal Teknodik, 12

Sopiah, N. (2012). Penggunaan Metode Analisis dan Rancangan Beorientasi Objek pada Web Jurnal Ilmiah Terpadu. Seminar Nasional Informatika. UPN "Veteran" Yogyakarta

Yusuf, M., Wahyuni, S., \& Saim M. (2010). E-learning Menggunakan Standar Learning Technology System Architecture (LTSA). Jurnal Universitas Trunojoyo. 1(2) 